\title{
Rathke cleft cysts in pediatric patients: presentation, surgical management, and postoperative outcomes
}

\author{
Arman Jahangiri, B.S., ${ }^{1}$ Annette M. Molinaro, Ph.D., ${ }^{2}$ Phiroz E. Tarapore, M.D., ${ }^{2}$ \\ Lewis Blevins JR., M.D., ${ }^{2,3}$ Kurtis I. Auguste, M.D., ,,4 Nalin Gupta, M.D., PH.D.,, 4 \\ Sandeep Kunwar, M.D., ${ }^{2,3}$ And Manish K. Aghi, M.D., Ph.D. ${ }^{2,3}$ \\ ${ }^{1}$ University of Texas Southwestern Medical School, Dallas, Texas; ${ }^{2}$ Departments of ${ }^{2}$ Neurological Surgery and \\ ${ }^{4}$ Pediatrics, University of California at San Francisco; and ${ }^{3}$ The California Center for Pituitary Disorders at \\ UCSF, San Francisco, California
}

\begin{abstract}
Object. Rathke cleft cysts (RCC) are benign sellar lesions most often found in adults, and more infrequently in children. They are generally asymptomatic but sometimes require surgical treatment through a transsphenoidal corridor. The purpose of this study was to compare adult versus pediatric cases of RCC.

Methods. The authors retrospectively reviewed presenting symptoms, MR imaging findings, laboratory study results, and pathological findings in 147 adult and 14 pediatric patients who underwent surgery for treatment of RCCs at the University of Californial at San Francisco between 1996 and 2008.

Results. In both the adult and pediatric groups, most patients were female (78\% of adults, $79 \%$ of pediatric patients, $\mathrm{p}=0.9$ ). Headache was the most common symptom in both groups (reported by $50 \%$ of pediatric patients and $33 \%$ of adults, $\mathrm{p}=0.2)$. Preoperative hypopituitarism occurred in $41 \%$ of adults and $45 \%$ of pediatric patients $(\mathrm{p}=$ 0.8 ). Growth delay, a uniquely pediatric finding, was a presenting sign in $29 \%$ of pediatric patients. Visual complaints were a presenting symptom in $16 \%$ of adult and $7 \%$ of pediatric patients $(p=0.4)$. There was no difference between median cyst size in adults versus pediatric patients $(1.2 \mathrm{~cm}$ in both, $\mathrm{p}=0.7)$. Temporary or permanent postoperative diabetes insipidus occurred in $12 \%$ of adults and $21 \%$ of pediatric patients $(p=0.4)$. Kaplan-Meier analysis revealed an $8 \%$ RCC recurrence rate at 2 years for each group $(\mathrm{p}=0.5)$.

Conclusions. The incidence of RCCs is much lower in the pediatric population; however, symptoms, imaging findings, and outcomes are similar, suggesting that pediatric RCCs arise from growth of remnants of the embryonic Rathke pouch earlier in life than adult RCCs but do not differ in any other way. It is important to consider RCCs in the differential diagnosis when pediatric patients present with visual impairment, unexplained headache, or hypopituitarism including growth delay. Although the average RCC size was similar in our pediatric and adult patient groups, the smaller size of the pituitary gland in pediatric patients suggests an increased relative RCC size.
\end{abstract}

(DOI: 10.3171/2011.5.FOCUS1178)

\section{KeY Words • pediatric surgery - Rathke cleft cyst • pituitary lesion • transsphenoidal approach}

$\mathrm{R}$ ATHKE cleft cysts are nonneoplastic cystic lesions containing mucoid material in the sellar region. ${ }^{3,30}$ Rathke cleft cysts (RCCs) and craniopharyngiomas both form from the remnants of the embryonic Rathke pouch, ${ }^{3,30}$ which normally reduces to a narrow cleft by the 6th week of embryonic life..$^{30}$ The two types of lesions are closely related and may represent a continuum from the simpler RCCs to the more complex craniopharyngiomas. ${ }^{14}$ One difference is that RCCs are rare in children (Table 1), while craniopharyngiomas, particularly the adamantinomatous variety, are much more com-

Abbreviations used in this paper: $\mathrm{GH}=$ growth hormone; $\mathrm{IGF}-\mathrm{I}=$ insulin-like growth factor-I; RCC = Rathke cleft cyst. mon in children and represent $10 \%$ of all pediatric brain tumors. ${ }^{31}$ Although the prevalence of RCCs in adults is rather high, with RCCs found in $11 \%-22 \%$ of autopsies, ${ }^{26,28}$ most lesions are asymptomatic. ${ }^{23}$ The prevalence of RCCs in children, as determined by autopsy and MR imaging studies done for other reasons, is considerably less than in adults, and the asymptomatic RCCs that are identified in children are typically smaller than those found in adults. An autopsy study of 44 children under the age of 9 years, found all RCCs to be smaller than 2 $\mathrm{mm} .{ }^{28}$ In another study, ${ }^{27}$ asymptomatic cystic pituitary lesions were discovered on MR images in $1.2 \%$ of 341 patients younger than 15 years of age.

Adults with symptomatic RCCs may present with vi- 
TABLE 1: Summary of prior reports of RCCs in pediatric patients*

\begin{tabular}{|c|c|c|c|c|c|c|c|c|c|c|c|c|c|}
\hline \multirow[b]{2}{*}{ Authors \& Year } & \multirow[b]{2}{*}{$\begin{array}{l}\text { No. of } \\
\text { Ped } \\
\text { Pts }\end{array}$} & \multirow[b]{2}{*}{$\begin{array}{c}\% \\
\text { Female }\end{array}$} & \multicolumn{2}{|c|}{ Pt Age (yrs) } & \multirow[b]{2}{*}{$\begin{array}{l}\% \text { w/ } \\
\mathrm{HA}\end{array}$} & \multirow[b]{2}{*}{$\begin{array}{c}\% \text { wl } \\
\text { Vis } \\
\text { Dysfx }\end{array}$} & \multirow[b]{2}{*}{$\begin{array}{c}\% \text { w/ } \\
\text { Incidental } \\
\text { Finding }\end{array}$} & \multirow[b]{2}{*}{$\begin{array}{l}\% \text { wl } \\
\text { Preop } \\
\text { Hypopit }\end{array}$} & \multicolumn{2}{|c|}{ Cyst Size (cm) } & & \multirow[b]{2}{*}{$\begin{array}{l}\text { Med } \\
\text { FU } \\
\text { (mos) }\end{array}$} & \multirow[b]{2}{*}{$\%$ Recurrence } \\
\hline & & & Med & Range & & & & & Med & Range & Treatment & & \\
\hline $\begin{array}{l}\text { Lim \& Yang, } \\
\quad 2010\end{array}$ & 44 & 50 & 10.1 & $0.1-18.2$ & 65 & 19 & 30 & 61 & NR & NR & $\begin{array}{l}65.9 \% \text { conserva- } \\
\text { ive, } 34.1 \% \text { sur- } \\
\text { gical }\end{array}$ & 15.6 & NR \\
\hline $\begin{array}{l}\text { Katavetin et al., } \\
2010\end{array}$ & 13 & 85 & 14 & $7-17$ & 85 & 15 & 0 & 15 & 1.22 & $0.7-1.5$ & $\begin{array}{l}69 \% \text { conserva- } \\
\text { tive, } 31 \% \text { TSS }\end{array}$ & 21. & $\begin{array}{l}25 \text { (1 of } 4 \text { surgi- } \\
\text { cal cases) }\end{array}$ \\
\hline $\begin{array}{l}\text { Evliyaoglu et } \\
\text { al., } 2010\end{array}$ & 1 & 100 & 7 & NA & 0 & 0 & 0 & 100 & 0.67 & NA & microsurgery & 24 & 0 \\
\hline $\begin{array}{l}\text { Locatelli et al., } \\
2010\end{array}$ & 4 & NR & 10.5 & NR & $N R$ & NR & $N R$ & NR & NR & NR & NR & NR & NR \\
\hline $\begin{array}{l}\text { Frazier et al., } \\
2008\end{array}$ & 1 & 100 & 14 & NA & 100 & 0 & 0 & 0 & 3 & NA & TSS & 8 & 0 \\
\hline $\begin{array}{l}\text { Takanashi et } \\
\text { al., } 2005\end{array}$ & 4 & 25 & 2 & $1-4$ & 0 & 0 & 100 & 0 & 0.56 & $0.4-0.85$ & none & NR & NA \\
\hline $\begin{array}{l}\text { Kim et al., } \\
2004\end{array}$ & 1 & 100 & 11 & NA & 100 & 100 & 0 & 0 & 1.6 & NA & TSS & 4 & 100 \\
\hline Im et al., 2003 & 1 & 100 & 12 & NA & 100 & 100 & 0 & 100 & 1.6 & NA & TSS & 26 & 0 \\
\hline $\begin{array}{l}\text { Israel et al., } \\
2000\end{array}$ & 1 & 100 & 13 & NA & 0 & 100 & 0 & 0 & 1.5 & NA & rt craniotomy & 5 & 100 \\
\hline $\begin{array}{l}\text { Setian et al., } \\
1999\end{array}$ & 1 & 0 & 8 & NA & 0 & 0 & 0 & 100 & 1 & NA & TSS & NR & NR \\
\hline $\begin{array}{l}\text { Christophe et } \\
\text { al., } 1993\end{array}$ & 7 & 29 & 4.29 & $0.5-13$ & 29 & 0 & 43 & 14.28 & 1.4 & $0.8-2.0 \dagger$ & $\begin{array}{c}71 \% \text { observation, } \\
29 \% \text { TSS }\end{array}$ & $24 \dagger$ & $0 \dagger$ \\
\hline $\begin{array}{l}\text { Voelker et al., } \\
1991\end{array}$ & 1 & 100 & 15 & NA & 100 & 0 & 0 & 100 & NR & NA & $\begin{array}{l}\text { rt frontal craniot- } \\
\text { omy }\end{array}$ & 84 & 0 \\
\hline $\begin{array}{c}\text { Towbin et al., } \\
1987\end{array}$ & 1 & 0 & 10 & NA & 100 & 0 & 0 & 100 & NR & NA & NR & NR & NR \\
\hline
\end{tabular}

* FU = follow-up; HA = headache; Hypopit = hypopituitarism; Med = median; NA = not applicable; $\mathrm{NR}=$ not recorded; Ped = pediatric; Pt = patient; $\mathrm{TSS}$ $=$ transphenoidal surgery; Vis Dysfx = Visual Dysfunction.

$\dagger$ In the 2 transphenoidal surgery cases.

sual loss, headaches, or endocrinopathy due to the mass effect of the cyst on adjacent structures such as the optic apparatus, dura mater, or pituitary gland, respectively. ${ }^{23}$ Although there are copious data describing the manifestations and outcome of RCCs, most are derived from case series of adult patients and little data are available on the presentation or treatment outcomes of RCCs in children. We therefore examined clinical manifestations and outcomes of RCCs in patients 18 years of age or younger who were surgically treated at the University of California at San Francisco and investigated for distinguishing factors in presentation, surgical outcome, and recurrence as compared with our cohort of adult patients who underwent surgery for treatment of RCCs during the same time interval. In particular, since craniopharyngioma, a more aggressive lesion on the opposite end of a continuum of ectodermal derivatives from RCCs, is more common in the pediatric population than in adults, we sought to determine, working within the limitations of the small sample size of pediatric cases of RCC, whether we could identify any examples of more aggressive features in
RCCs in children, particularly in terms of cyst size, squamous metaplasia, inflammation, postoperative morbidity such as diabetes insipidus, or RCC recurrence.

\section{Methods}

\section{Study Design and Population}

We retrospectively reviewed clinical records and imaging studies of 161 patients with RCCs who underwent their first operation at our institution (160 patients) or at another institution followed by recurrence surgically treated at our institution (1 patient) between 1996 and 2008. The patient's age at the time of his or her initial operation was used to represent the age at diagnosis. This study was approved by the University of California at San Francisco Committee on Human Research.

\section{Surgical Technique}

The endonasal transsphenoidal microsurgical technique was performed by 3 surgeons (Charles B. Wilson, 
44 cases; S.K., 111 cases; and M.K.A., 6 cases) as described elsewhere. ${ }^{24} \mathrm{~A}$ rectangular dural window was created and the edges were coagulated, after which cystic fluid was either expressed spontaneously or an inverted T-shaped incision was made in the pituitary gland to enter the cyst cavity if the gland was anteriorly displaced. For most cysts, further nodular components were removed using suction and ring curettes. In some cases, the visualization of the pituitary fossa was facilitated by the use of a rigid endoscope. In treating patients with RCCs larger than $1 \mathrm{~cm}$ in diameter, the resection cavity was packed loosely with an abdominal fat graft, while in those with smaller RCCs the cavity was packed with Gelfoam. Reconstruction of the sellar floor was performed as described elsewhere. ${ }^{24}$

\section{Endocrine Assessment}

A preoperative hormonal abnormality was defined as a hormone level outside the normal range for the reporting laboratory. "Postoperative normalization" was defined as a low preoperative level becoming normal postoperatively in a particular hormonal axis. "Postoperative worsening" in pituitary function was defined as any new abnormality in anterior pituitary function, or new need for long-term hormone replacement. Patients were not considered to have worsened function if they transiently required hormone replacement for less than 6 months following surgery (for example, short-term cortisol replacement), but eventually had normal function.

\section{Pathological Review}

We reviewed all cases for the pathological confirmation of an RCC diagnosis as evidenced by a nonneoplastic epithelial cyst with well-differentiated cuboidal or columnar epithelial ciliated cells. The pathology reports were further analyzed for changes in the cyst wall such as inflammation or squamous metaplasia.

\section{Statistical Analysis}

The Fisher exact test was used to compare categorical variables between the pediatric and adult groups. The Wilcoxon rank-sum test was used to compare continuous variables between the 2 groups. The Kaplan-Meier estimator and log-rank test were used to compare the survival functions of the pediatric and adult groups. Given the exploratory nature of the analyses, $\mathrm{p}$ values below 0.05 were considered statistically significant with no correction for multiple testing.

\section{Results}

\section{Patient Population}

The overall patient cohort was separated into 2 categories based on the patient's age at the time of surgery: 1) an adult group, comprising 147 patients (91\%) who were over the age of 18 years at surgery, and 2) a pediatric group, comprising 14 patients $(9 \%)$ were 18 years or younger at surgery. Of the 147 adult patients, 114 (78\%) were female, and $11(79 \%)$ of the pediatric patients were female $(\mathrm{p}=0.9)$. The median age of the adult patients was 42 years (range 19-81 years), whereas the pediatric group had a median age of 16 years (range $3-18$ years) (Tables 2 and 3$)$.

\section{Presenting Signs and Symptoms}

The presenting signs and symptoms in the 2 groups are compared in Table 3. Headaches were a presenting complaint in $48(33 \%)$ of 147 adults and $7(50 \%)$ of 14 children $(\mathrm{p}=0.2)$. Twenty-four $(16 \%)$ of 147 adults and $1(7 \%)$ of 14 children presented with visual symptoms (p $=0.4)$. Two adults (1\%) and 1 child $(7 \%)$ presented with diabetes insipidus $(\mathrm{p}=0.2)$. Eleven $(7 \%)$ of 147 adult and $2(14 \%)$ of 14 pediatric RCCs were found incidentally on imaging $(\mathrm{p}=0.3)$.

TABLE 2: Summary of presenting findings in pediatric patients with RCCs in this series*

\begin{tabular}{|c|c|c|c|c|c|c|}
\hline Case No. & Age (yrs), Sex & $\mathrm{HA}$ & Vis Dysfx & Endocrine (preop hypopituitarism) & $\begin{array}{l}\text { RCC as Incidental } \\
\text { Finding }\end{array}$ & $\begin{array}{c}\text { Cyst Size } \\
\text { (diameter in cm) }\end{array}$ \\
\hline 1 & $15, \mathrm{~F}$ & - & - & + & + & 2.0 \\
\hline 2 & $17, \mathrm{M}$ & - & - & - & + & 1.5 \\
\hline 3 & $3, \mathrm{~F}$ & - & - & - & - & 1.3 \\
\hline 4 & $16, F$ & + & - & - & - & 0.7 \\
\hline 5 & $16, \mathrm{~F}$ & + & - & - & - & 1.1 \\
\hline 6 & $16, M$ & - & - & + & - & 1.9 \\
\hline 7 & $14, \mathrm{M}$ & + & - & - & - & 1.0 \\
\hline 8 & $17, \mathrm{~F}$ & - & - & + & - & 1.0 \\
\hline 9 & $17, \mathrm{~F}$ & - & - & - & - & 1.5 \\
\hline 10 & $17, \mathrm{~F}$ & + & - & + & - & 1.1 \\
\hline 11 & $18, F$ & + & - & - & - & 1.5 \\
\hline 12 & $10, F$ & - & - & + & - & 0.9 \\
\hline 13 & $15, F$ & + & - & - & - & 1.5 \\
\hline 14 & $15, F$ & + & + & - & - & 1.1 \\
\hline
\end{tabular}


TABLE 3: Comparison of preoperative characteristics in 147 adult and 14 pediatric patients with RCCs*

\begin{tabular}{|c|c|c|c|c|}
\hline Characteristic & Total Population & Adults & Ped Pts & $\mathrm{p}$ Value \\
\hline \multicolumn{5}{|l|}{ age (yrs) } \\
\hline median & 39 & 42 & 16 & \\
\hline range & $3-81$ & $19-81$ & $3-18$ & \\
\hline female sex & $125 / 161(78)$ & $114 / 147(78)$ & $11 / 14(79)$ & 0.9 \\
\hline \multicolumn{5}{|l|}{ presenting signs \& symptoms } \\
\hline $\mathrm{HA}$ & $55 / 161(34)$ & $48 / 147(33)$ & $7 / 14(50)$ & 0.2 \\
\hline growth delay & $3 / 161(2)$ & 0 & $3 / 14(21)$ & $<0.001$ \\
\hline vis dysfx & $25 / 161(16)$ & $24 / 147(16)$ & $1 / 14(7)$ & 0.4 \\
\hline symptomatic hyperprolactinemia & 24/161 (15) & $24 / 147(16)$ & $0 / 14(0)$ & 0.1 \\
\hline symptomatic hypopituitarism & 20/161 (12) & $18 / 147(12)$ & 2/14 (14) & 0.9 \\
\hline RCC as incidental finding & $13 / 161(8)$ & $11 / 147(7)$ & $2 / 14(14)$ & 0.3 \\
\hline \multicolumn{5}{|l|}{ preop laboratory findings } \\
\hline hypopituitarism & $54 / 132(41)$ & 49/121 (40) & $5 / 11(45)$ & 0.8 \\
\hline hyperprolactinemia & 25/161 (16) & $24 / 147(16)$ & $1 / 14(7)$ & 0.7 \\
\hline \multicolumn{5}{|l|}{ preop MRI findings } \\
\hline median RCC diameter \pm SD & $1.2 \pm 0.5 \mathrm{~cm}$ & $1.2 \pm 0.5 \mathrm{~cm}$ & $1.2 \pm 0.4 \mathrm{~cm}$ & 0.7 \\
\hline high T1 signal intensity† & $58 / 101(57)$ & $54 / 93(58)$ & $4 / 8(50)$ & 0.7 \\
\hline preop DI & $3 / 161(2)$ & $2 / 147(1)$ & $1 / 14(7)$ & 0.2 \\
\hline
\end{tabular}

* Values represent numbers of patients (\%) unless otherwise indicated. p values $<0.05$ were considered statistically significant. Abbreviation: $\mathrm{DI}=$ diabetes insipidus.

† Lesions with high signal intensity on T1-weighted MR images were interpreted as cystic fluid with a high protein content.

\section{Preoperative Laboratory Results}

Preoperative laboratory studies revealed that 49 $(40 \%)$ of 121 adults had preoperative hypopituitarism in at least one anterior pituitary hormonal axis, including $4(36 \%)$ of the 11 adults with incidentally found RCCs. These proportions were similar to the $5(45 \%)$ of 11 pediatric patients with preoperative hypopituitarism $(\mathrm{p}=0.8)$, including $1(50 \%)$ of the 2 with incidentally found RCCs. Three of the 14 pediatric patients presented with growth arrest. Of these 3 patients, 2 had low levels of serum GH and IGF-I. Three additional pediatric patients had low levels of serum GH and IGF-I but did not exhibit growth arrest.

\section{Preoperative Imaging}

Preoperative MR imaging revealed a median cyst diameter of $1.2 \mathrm{~cm}$ in adult patients, identical to that of pediatric patients $(\mathrm{p}=0.7)$. High signal intensity on T1-weighted images, consistent with proteinaceous cyst fluid, was present in 54 (58\%) of 93 RCCs in adults and 4 $(50 \%)$ of $8 \mathrm{RCCs}$ in the pediatric patient group $(\mathrm{p}=0.7)$. Suprasellar extension occurred in $47(34 \%)$ of 138 cysts in adults, compared with $2(15 \%)$ of 13 cysts in pediatric patients $(\mathrm{p}=0.2)$

\section{Postoperative Endocrine Function}

Diabetes insipidus (either temporary or permanent) related to the initial operation occurred postoperatively in $18(12 \%)$ of 147 adults; this rate was comparable to the postoperative occurrence of diabetes insipidus in $3(21 \%)$ of 14 pediatric patients $(\mathrm{p}=0.4)$. Twenty-four $(56 \%)$ of
43 abnormal axes in adult patients normalized postoperatively, comparable to the $3(43 \%)$ of 7 abnormal axes that normalized postoperatively in the pediatric group ( $p$ $=0.6)$. Thirteen $(45 \%)$ of 29 adults and $2(40 \%)$ of 5 pediatric patients with low preoperative laboratory values had normalization of at least one axis postoperatively. None of the 3 patients who presented with growth arrest resumed growth postoperatively, and none of the 3 patients who presented with low GH and IGF-I values without growth arrest had normalization of laboratory values postoperatively. Ten (11\%) of 93 adults had new postoperative hypopituitarism, comparable to the $1(10 \%)$ of 10 pediatric patients with new postoperative hypopituitarism $(\mathrm{p}=0.9)$. No pediatric patient had new low GH or IGF-I levels postoperatively.

\section{Postoperative Imaging}

Rathke cleft cysts that were incompletely resected during the first operation were noted on postoperative MR imaging results. Subtotal resection was noted in $22(15 \%)$ of 147 adults and $2(14 \%)$ of 14 pediatric patients $(\mathrm{p}=0.9)$.

\section{Microbiology}

In cases with purulent fluid within the RCC cavity, intraoperative specimens were sent for culturing. Cyst cultures were obtained in $23(16 \%)$ of the 147 adults as compared with $1(7 \%)$ of the 14 pediatric patients $(\mathrm{p}=$ 0.7). Culture results were positive for microbial growth in $11(48 \%)$ of the 23 cases involving adults; in the single pediatric case in which purulent fluid was found, culture of the specimen obtained in the first operation was nega- 
tive for microbial growth. This specific case led to 2 more operations due to recurrence and specimens were sent for culture each time. The second operation also resulted in a negative culture, with the final operation resulting in a positive culture.

\section{Pathological Features}

Inflammation occurred in $17(12 \%)$ of 147 adults and $3(21 \%)$ of 14 pediatric patients $(\mathrm{p}=0.4)$, whereas squamous metaplasia occurred in $13(9 \%)$ of 147 adults and 1 $(7 \%)$ of 14 pediatric patients $(\mathrm{p}=0.9)$.

\section{Recurrence Rates}

The median duration of radiological follow-up was 23 months in adult patients and 38 months in pediatric patients. The rate of recurrence or postoperative radiological progression was similar in the 2 groups with the adult recurrence rate of $12 \%$ (recurrence occurring in 18 of 147 cases) and the pediatric recurrence rate of $14 \%$ (2 of 14 cases), yielding Kaplan-Meier estimates of $8 \%$ for each group (pediatric and adult) at 2 years $(\mathrm{p}=0.5)$.

\section{Discussion}

In this study, we compared the presenting symptoms and treatment of RCCs in adults and pediatric patients at our institution over a 12-year period. Although our sample size was small, this likely reflects the rarity of RCCs in children, and our series still represents one of the largest series of pediatric cases of RCC reported to date (Table 1). Moreover, it is the first to compare outcomes in pediatric and adult patients with RCCs treated by the same surgical group during the same study interval, with similar surgical technique being used in both cohorts. Recognizing the limitations of the small sample size due to the rarity of RCCs in children, we did not find significant differences in symptoms, imaging findings, pathological findings, morbidity, or recurrence of RCCs between the adult and pediatric groups.

Although we found no difference in median cyst size between the pediatric and adult groups, when one considers that the normal pituitary height in children 15 years or younger ranges from 0.35 to $0.53 \mathrm{~cm}$ compared with the adult pituitary height, which is normally $0.69 \mathrm{~cm}$ on average, the cyst size is still relatively larger in the pediatric group. ${ }^{1,13}$ Our findings suggest that RCCs in pediatric patients are just a faster growing version of the same benign entity witnessed in the adult population.

In our series, we considered headache to be a symptom, regardless of RCC size-given a recent report in which $90 \%$ of patients with headaches and pituitary lesions less than $1 \mathrm{~cm}$ in diameter had pain improvement after surgery. ${ }^{11}$ While our one patient with headache and a cyst smaller than $1 \mathrm{~cm}$ in diameter did not experience postoperative improvement in headache, if we consider headache a symptom of RCC, then 12 of the 14 pediatric patients in our series were symptomatic, with one of the other 2 pediatric patients having laboratory evidence of hypopituitarism, and the other having an incidentally found 1.5-cm RCC with normal endocrine laboratory values but slight mass effect on the overlying optic chiasm on MR imaging. As described earlier, incidentally found RCCs are less common in children than in adults, which likely reflects a combination of the more frequent usage of cranial imaging in adults and the natural history of $\mathrm{RCCs}$, which is slowly progressive - they take time to become radiologically detectable. Our series did not contain any incidentally found RCCs in pediatric patients who were managed with observation (serial imaging) rather than surgery, a few of which have been reported in the literature (Table 1). The largest series of incidentally found RCCs that were managed with observation comprised 115 RCCs in adult patients. The patients were followed up with serial imaging over a mean of 27 months. During this period, $4 \%$ of the cysts grew and $22 \%$ decreased in size, which led those authors to suggest observing all incidentally found RCCs until evidence of growth, although their series did not correlate the tendency to grow or regress with size at diagnosis. ${ }^{22}$ Despite the low morbidity described in operating on RCCs in pediatric patients in our series, until further information is derived correlating the natural history of RCCs with their size at diagnosis, the decision to observe an incidentally found RCC in a pediatric patient with normal laboratory values and no chiasmatic compression is reasonable.

One surgical technique that is rapidly gaining acceptance in the treatment of pituitary lesions is the endoscopic endonasal approach. ${ }^{5}$ In the pediatric population, where access through the nares is a challenge, this technique may offer improved visualization. ${ }^{8,12}$ This technique, however, is not without its own limitations. In the pediatric population, the small nares can interfere with the introduction of the endoscope unless a concurrent turbinectomy or ethmoidectomy is performed. These procedures increase the likelihood of postoperative rhinological complications, including empty nose syndrome. ${ }^{6,15}$ In the future, if access limitations can be overcome, endoscopy may allow for improved visualization of the suprasellar space and medial cavernous sinus. ${ }^{4}$ This technique may thus improve the surgeon's ability to identify and address residual disease, an important advantage in cases of hormonally active pituitary tumors where complete removal of all tumor cells is required,,$^{10}$ but of less concern with an RCC, where cyst drainage and partial wall obliteration is associated with a comparable recurrence rate and less endocrine morbidity than complete wall resection. ${ }^{2}$ Given the lack of nasal morbidity and postoperative CSF leak in our series, it is questionable whether an endoscopic approach would confer an advantage in either outcome or morbidity.

Limitations to our study include its retrospective nature and the fact that, while it represents one of the largest surgical series of pediatric RCCs to date (Table 1), the sample size is still small, which limits the ability to definitively identify differences between pediatric and adult RCCs. Given the rarity of pediatric RCCs, a prospective multiinstitutional database of pediatric and adult RCCs would be the best means of confirming our findings in a manner free of these limitations.

\section{Conclusions}

We found that the presentation of pediatric patients 
with RCCs is similar to that of adults with these lesionswith the exception of delayed growth, which is a uniquely pediatric manifestation-and that the surgical morbidity in pediatric patients was comparable to that seen in adult patients. These findings suggest that surgery should be offered for symptomatic children with RCCs, and is a consideration for incidentally found RCCs whose size suggests a high likelihood of future growth and future symptoms.

\section{Disclosure}

The authors report no conflict of interest concerning the materials or methods used in this study or the findings specified in this paper.

Author contributions to the study and manuscript preparation include the following. Conception and design: Aghi. Acquisition of data: Aghi, Jahangiri. Analysis and interpretation of data: Aghi, Jahangiri. Drafting the article: Aghi, Jahangiri. Critically revising the article: all authors. Statistical analysis: Aghi, Molinaro.

\section{References}

1. Argyropoulou M, Perignon F, Brunelle F, Brauner R, Rappaport R: Height of normal pituitary gland as a function of age evaluated by magnetic resonance imaging in children. Pediatr Radiol 21:247-249, 1991

2. Benveniste RJ, King WA, Walsh J, Lee JS, Naidich TP, Post KD: Surgery for Rathke cleft cysts: technical considerations and outcomes. J Neurosurg 101:577-584, 2004

3. Berry RG, Schlezinger NS: Rathke-cleft cysts. Arch Neurol 1:48-58, 1959

4. Cappabianca P, Cavallo LM, de Divitiis O, Solari D, Esposito F, Colao A: Endoscopic pituitary surgery. Pituitary 11:385390, 2008

5. Carrau RL, Kassam AB, Snyderman CH: Pituitary surgery. Otolaryngol Clin North Am 34:1143-1155, ix, 2001

6. Chhabra N, Houser SM: The diagnosis and management of empty nose syndrome. Otolaryngol Clin North Am 42:311330, ix, 2009

7. Christophe C, Flamant-Durand J, Hanquinet S, Heinrichs C, Raftopoulos C, Sariban E, et al: MRI in seven cases of Rathke's cleft cyst in infants and children. Pediatr Radiol 23:79-82, 1993

8. de Divitiis E, Cappabianca P, Gangemi M, Cavallo LM: The role of the endoscopic transsphenoidal approach in pediatric neurosurgery. Childs Nerv Syst 16:692-696, 2000

9. Evliyaoglu O, Evliyaoglu C, Ayva S: Rathke cleft cyst in seven-year-old girl presenting with central diabetes insipidus and review of literature. J Pediatr Endocrinol Metab 23:525529,2010

10. Fernandez-Miranda JC, Prevedello DM, Gardner P, Carrau R, Snyderman $\mathrm{CH}$, Kassam AB: Endonasal endoscopic pituitary surgery: is it a matter of fashion? Acta Neurochir (Wien) 152:1281-1282, 2010

11. Fleseriu M, Yedinak C, Campbell C, Delashaw JB: Significant headache improvement after transsphenoidal surgery in patients with small sellar lesions. Clinical article. J Neurosurg 110:354-358, 2009

12. Frazier JL, Chaichana K, Jallo GI, Quiñones-Hinojosa A: Combined endoscopic and microscopic management of pediatric pituitary region tumors through one nostril: technical note with case illustrations. Childs Nerv Syst 24:1469-1478, 2008

13. Hall WA, Luciano MG, Doppman JL, Patronas NJ, Oldfield EH: Pituitary magnetic resonance imaging in normal human volunteers: occult adenomas in the general population. Ann Intern Med 120:817-820, 1994
14. Harrison MJ, Morgello S, Post KD: Epithelial cystic lesions of the sellar and parasellar region: a continuum of ectodermal derivatives? J Neurosurg 80:1018-1025, 1994

15. Houser SM: Empty nose syndrome associated with middle turbinate resection. Otolaryngol Head Neck Surg 135:972973, 2006

16. Im SH, Wang KC, Kim SK, Chung YN, Kim HS, Lee CH, et al: Transsphenoidal microsurgery for pediatric craniopharyngioma: special considerations regarding indications and method. Pediatr Neurosurg 39:97-103, 2003

17. Israel ZH, Yacoub M, Gomori JM, Dotan S, Fellig Y, Shoshan Y, et al: Rathke's cleft cyst abscess. Pediatr Neurosurg 33: $159-161,2000$

18. Katavetin P, Cheunsuchon P, Grant E, Boepple PA, HedleyWhyte ET, Misra M, et al: Rathke's cleft cysts in children and adolescents: association with female puberty. J Pediatr Endocrinol Metab 23:1175-1180, 2010

19. Kim JE, Kim JH, Kim OL, Paek SH, Kim DG, Chi JG, et al: Surgical treatment of symptomatic Rathke cleft cysts: clinical features and results with special attention to recurrence. J Neurosurg 100:33-40, 2004

20. Lim HH, Yang SW: Risk factor for pituitary dysfunction in children and adolescents with Rathke's cleft cysts. Korean J Pediatr 53:759-765, 2010

21. Locatelli D, Massimi L, Rigante M, Custodi V, Paludetti G, Castelnuovo P, et al: Endoscopic endonasal transsphenoidal surgery for sellar tumors in children. Int J Pediatr Otorhinolaryngol 74:1298-1302, 2010

22. Oyama K, Sanno N, Tahara S, Teramoto A: Management of pituitary incidentalomas: according to a survey of pituitary incidentalomas in Japan. Semin Ultrasound CT MR 26:4750, 2005

23. Raper DM, Besser M: Clinical features, management and recurrence of symptomatic Rathke's cleft cyst. J Clin Neurosci 16:385-389, 2009

24. Sanai N, Quiñones-Hinojosa A, Narvid J, Kunwar S: Safety and efficacy of the direct endonasal transsphenoidal approach for challenging sellar tumors. J Neurooncol 87:317-325, 2008

25. Setian N, Aguiar CH, Galvão JA, Crivellaro CE, Dichtchekenian V, Damiani D: Rathke's cleft cyst as a cause of growth hormone deficiency and micropenis. Childs Nerv Syst 15: 271-273, 1999

26. Shanklin WM: On the presence of cysts in the human pituitary. Anat Rec 104:379-407, 1949

27. Takanashi J, Tada H, Barkovich AJ, Saeki N, Kohno Y: Pituitary cysts in childhood evaluated by MR imaging. AJNR Am J Neuroradiol 26:2144-2147, 2005

28. Teramoto A, Hirakawa K, Sanno N, Osamura Y: Incidental pituitary lesions in 1,000 unselected autopsy specimens. Radiology 193:161-164, 1994

29. Towbin RB, Ball WS, Kaufman RA: Pediatric case of the day. Rathke's cleft cyst. Radiographics 7:385-388, 1987

30. Voelker JL, Campbell RL, Muller J: Clinical, radiographic, and pathological features of symptomatic Rathke's cleft cysts. J Neurosurg 74:535-544, 1991

31. Zada G, Lin N, Ojerholm E, Ramkissoon S, Laws ER: Craniopharyngioma and other cystic epithelial lesions of the sellar region: a review of clinical, imaging, and histopathological relationships. Neurosurg Focus 28(4):E4, 2010

Manuscript submitted March 13, 2011.

Accepted May 2, 2011.

Address correspondence to: Manish K. Aghi, M.D., Ph.D., Department of Neurological Surgery, University of California at San Francisco, 505 Parnassus Avenue, Room M779, San Francisco, California 94143.email: AghiM@ neurosurg.ucsf.edu. 